\title{
Impact Analysis of Hard Roof on the Morphological Evolution of Stress Arch
}

\author{
Xia Binwei ${ }^{1,2 *}$, Fu Yuanhao ${ }^{1,2}$, Zhang Xuan ${ }^{1,2}$, Gong Tao ${ }^{1,2}$ and Hu Ke ${ }^{3}$ \\ ${ }^{1}$ State Key Laboratory of Coal Mine Disaster Dynamics and Control, Chongqing University, Chongqing 400044, China \\ ${ }^{2}$ National \& Local Joint Engineering Laboratory of Gas Drainage in Complex Coal Seam, Chongqing University, Chongqing \\ 400030, China \\ ${ }^{3}$ Institute of Mining and Special Civil Engineering, TU Freiberg, Freiberg 09599, Germany
}

Received 9 January 2019; Accepted 15 March 2019

\begin{abstract}
A reasonable theoretical model of the stress arch (SA) is the key to explore its morphological evolution, but the existing theoretical models of the SA have issues, such as simple parameters and disregarding hard roof (HF). To study the influence of motion-induced fracture of the HF on morphological evolution of stress arch (MESA), the dynamic relationship between the fracturing motion of the HF and evolutionary expansion of the SA was analyzed and a calculation model of coal/rock mass interfacial stress was introduced for theoretical SA model optimization. Hence, a recursive algorithm was used to derive the morphological evolution equation of the stress arch (MEESA) under the influence of the HF, and Flac3D was used to simulate the MESA. Results indicate that the SA is formed in the overlying strata after mining, and SA morphology is controlled by the HF and experiences dynamic evolution with the fracturing motion of the HF. Before the SA expands to HF, it presents arch-shaped free expansion. After SA expands to HF, HF has the shielding effect on longitudinal expansion of the SA, thereby SA presents semi-arch-shaped transverse expansion, and HF has a constraining effect on the SA and SA goes through longitudinal expansion rapidly after HF is fractured, therefore SA presents calabash-shaped expansion. MEESA fits in well with the numerical experimental result. Hence, MEESA can be used to describe SA morphologies accurately. The conclusions in this study can provide a theoretical reference for mine pressure control.
\end{abstract}

Keywords: Stress arch, Hard roof, Morphological equation, Mining-induced stress field, Evolutionary characteristics

\section{Introduction}

Coal is the main energy source in China, and coal output has exceeded $1 / 3$ of the total coal output worldwide [1] with the frequent occurrence of coal production accidents, especially accidents caused by mine pressure behavior severely impair the safety and efficiency of coal mining. As an important research content in the field of mining pressure and strata control, stress field evolution in the mined overlying strata is important for the stability analysis of surrounding rocks, mine pressure behavior control, and reasonable roadway support [2,3]. Mining-induced stress is generally acquired through on-site measurement, but it is limited by stope arrangement, measurement cost, and measurement period. Measuring points cannot be arranged within a large scope of the mine, and the real-time tracking and monitoring of stress evolution during the mining process is difficult to realize. With the development of computer technologies [4, 5], numerical simulation methods have provided effective analysis means for numerous scholars in the in-depth study of the evolution of mining-induced stress field. Numerical simulation methods can be used to analyze the distribution and evolution characteristics of mininginduced stress field intuitively due to their low cost and high visualization degree. However, numerical methods cannot be used to investigate the evolutionary laws and formation

*E-mail address: xiabinwei_cqu@163.com

ISSN: 1791-2377 @ 2019 Eastern Macedonia and Thrace Institute of Technology. All rights reserved. doi:10.25103/iestr.121.18 mechanism of mining-induced stress theoretically due to certain limitations. Thus, the mechanical mechanism underlying mining-induced stress formation should be determined, and a reasonable analytical model of mininginduced stress field should be proposed.

After coal seam mining, an arched mining-induced stress concentration zone is formed in the overlying strata. To study the arched distribution phenomenon and formation mechanism of mining-induced stress field, some scholars have analyzed the on-site stress environment and proposed stress arch (SA) theories [6]. SA is an arched stress concentration zone consisting of heavily stressed beams formed in the overlying strata under the self-organizing effect and is an arch transfer path of surrounding rock loads in the stope. On the one hand, studies on SA have established theoretical SA models by using three-hingedarch model. On the other hand, researchers have studied arch stress distribution features and evolution laws of mininginduced stress field via numerical simulation methods. These studies have effectively explained the periodic weighting phenomenon on the working face, systematically investigated the evolutionary laws and stress distribution features in mining-induced stress field, and provided a theoretical foundation for the stability analysis of surrounding rocks in the stope, mine pressure behavior control, gas transport, and extraction effect. However, studies related to the SA do not analyze the morphological evolutionary characteristics of the SA under the influence of hard roof (HF) in the overlying strata. Coal seams reserved with HFs account for approximately $1 / 3$ of the total coal 
Xia Binwei, Fu Yuanhao, Zhang Xuan, Gong Tao, and Hu Ke/

\section{Journal of Engineering Science and Technology Review 12 (1) (2019) 153 - 162}

seams in China [7, 8]. HF can control the overlying strata motion and has a considerable importance on the SA evolution due to its high strength, considerable thickness, and strong integrity [9]. Meanwhile, existing SA models in the stope are controversial in terms of the value range of parameters used in the calculation of horizontal thrust of the arch foot, which results in the differences between analysis results and coal mining site.

Hence, the dynamic relation between the fracturing motion of the HF and evolutionary expansion of the SA was analyzed in this study, and the morphological evolutionary laws of the mining-induced SA under the influence of the $\mathrm{HF}$ were investigated to provide a theoretical foundation to control intense mine pressure behavior on the working face.

\section{State of the art}

Numerous scholars have carried out a considerable number of studies on SA in the overlying strata of the stope and played a guiding role in the engineering field. However, these studies mainly concentrate on the influences of mining width, lithology of surrounding rocks, mining rate and reserved coal pillars on morphological evolutionary features. Corkum et al. [5] analyzed the SA morphology in horizontal layered strata, developed 2D and 3D numerical simulation models on the basis of the measured field data, and applied these models to mine design. The developed model could be adopted well to mine design after calibration. Wang et al. [10] used Flac3D numerical simulation method to study influences of the surrounding rock strength, mining rate, and coal seam dip angle on SA morphology. The results indicated that as the advancing distance increased, the SA morphology in the horizontal coal seam changes from flat shape into arched shape and the arch thickness and the peak stress at the arch foot increased, thereby improving the strength of surrounding rocks in the stope and mining rate could improve SA stability. Vaziri et al. [11] found that an arched stress concentration zone was formed in the overlying strata after rock drilling in the soft strata and built an analytical model of the arched stress concentration zone, which was verified through numerical simulation. The results indicated that an arched plastic zone was formed in the overlying strata, where the zone undertook loads from the overlying strata, and the pressure was transferred into the two sides of the zone. Zhu et al. [12] used a numerical simulation method to study mining-induced SA morphology in the overlying strata during roof supporting by gob-side entry retaining and collar pillar reservation in the goaf. When gob-side entry retaining supporting method was adopted in the adjacent goaf, the SA presented half-space ellipsoidal shell morphology in the 3D space, and a wide pressure relief zone was formed in the overlying strata in the stope. When pillar reservation mining method was adopted, the mining-induced SA presented an $\mathrm{m}$ shape due to the stress concentration of coal pillars. Dynamic strata disasters within a large scope were caused by the instability of coal pillars. Shabanimashcool et al. [13] used an energy method to analyze the pressure arch, established an iterative solving algorithm, and used numerical simulation and experimental methods to verify the algorithm. The results indicated that the increase in elasticity modulus of the beam increased the horizontal stress of the pressure arch in the beam, thereby increasing sliding risks. Xie et al. [14] used a numerical simulation method to analyze the influence of lithological change of surrounding rocks on the mechanical features of the SA by combining with field measurement. The results indicated that, with the enhancement of lithology, the height of the SA was reduced and its shape turned from arch shape into flat shape. The bearing capacity systems of surrounding rocks differed due to different lithology. The SA in the soft rock was the main bearing capacity system. In the mediumhard rock, the SA and basic roof jointly undertook the loads in the overlying strata. In the hard rock, SA essentially overlapped with basic roof. On the basis of numerical simulation method, Li [15] found a natural SA existed nearby the tunnel wall and used SA theory to establish an artificial SA by anchor bolt supporting to improve the stability of the underground chamber. Angus et al. [16] studied the relationship between SA effect and seismic anisotropy through coupling simulation. The results indicated that the capabilities of the SA effect and two-side burdens that undertook loads restricted the overall change in effective stress and seismic anisotropy. Kong et al. [17] used a 2D numerical simulation method to study the formation features of the SA, defined the internal and external boundary lines and centroid line of the SA, and evaluated the influences of different geological intensity indices, burial depth, stress ratio, and geometric characteristics of the chamber on the SA morphology. The results indicated that the influences of burial depth and stress state on the stability of the SA were greater than those of geological intensity index and geometric features of the chamber.

The studies above have mainly used numerical simulation and similarity model methods to study the influences of structural parameters of the stope on the SA morphology. To carry out additional profound studies on the formation mechanism and distribution morphology of the SA, numerous scholars have established mechanical SA models from the angle of structural mechanics, derived morphological equations of the SA, and used models to study morphological evolutionary characteristics of the SA further. On the basis of physical similarity simulation and numerical simulation results, Yang et al. [18] analyzed the mechanical features of the pressure arch, built an analytical model, derived its morphological equation, and analyzed instability models of the pressure arch. Considering the side pressure coefficient and arched roof structure, Dancygier et al. [19] established an analytical response model of an overlying dynamic arch structure in the excavated chamber under the effect of ground static load and verified the model through example analysis. Yang et al. [20] established a 3D analytical model of the mining-induced SA, acquired the morphological evolution equation of mining-induced stress and scope of mining-induced fracture development, studied the relationship between the morphology of mining-induced SA and the parameters of mining-induced fracture development, and revealed the evolutionary characteristics of mining-induced SA and dynamic effect of mininginduced fracture development. The models mentioned above calculate the horizontal thrust of the SA foot by using the controversial rock Protodyakonov coefficient. Thus, the differences in calculated SA morphology are significant. These models also do not consider the influence of the HF on the morphological evolution of the SA (MESA).

Therefore, in this study, we analyzed the dynamic relationship between the fracturing motion of the HF and the evolution of the SA on the basis of SA theory. We also introduced the calculation model of the coal/rock mass interfacial stress to calculate the horizontal thrust of the arch foot and optimize the theoretical model of the SA. Therefore, a recursive algorithm was used to derive the morphological 
Xia Binwei, Fu Yuanhao, Zhang Xuan, Gong Tao, and Hu Ke/

Journal of Engineering Science and Technology Review 12 (1) (2019) 153 - 162

evolution equation of the SA (MEESA) under the influence of the HF. Numerical simulation was used to study the influence laws of motion-induced fracture of the HF under different advancing distances on the morphological evolution of the mining-induced SA, and the results were fitted with the derived equations for verification. The derived equations were finally applied in engineering practice. The study can provide a theoretical foundation for mine pressure control and stability analysis of surrounding rocks in the stope.

The rest of this study is organized as follows. In section 3 , the SA morphology under the influence of the HF was analyzed, the theoretical SA model was optimized, and the MEESA was derived. In section 4, the morphological evolution laws of the SA were studied by FLAC3D, and the MEESA was applied in engineering practice. The final section is a summary of the paper, where related conclusions are provided.

\section{Methodology}

3.1 SA morphological analysis under the influence of HF After coal seam mining, an arched fracture failure zone is formed in the overlying strata in the goaf (Fig. 1). An arched stress concentration zone is formed in the strata outside the fracture failure zone under the self-organizing effect, and this arched stress transfer path is called SA. When SA expands to the HF, SA cannot expand upward due to the bearing characteristics of the HF, and HF undertakes loads from the overlying strata due to plastic bending deformation. With the advancement of the working face, the HF goes through instability and fracture. A voussoir beam structure is formed in the failure zone, and combinational cantilever beams are formed in the overlying soft strata. Outside the failure zone, the SA experiences deformation. The secondlayer arched stress concentration zone on the basis of the HF is formed in the overlying strata, and complete arched stress transfer path cannot be formed in the overlying strata below the HF under the effect of the HF. Similarly, with the advancement of the working face, the SA morphology in the overlying strata outside the failure zone experiences continuous dynamic changes under the influence of motioninduced HF fracture. Meanwhile, the structures in the failure zone, such as voussoir beams and combinational cantilever beams, continuously expand and experience gradual evolution upward and toward the advancement direction with fracture of the HF and instability of the SA. The support resistance in the stope is derived from the strata motion inside the failure zone and sudden instability impact of the SA. The SA morphology under the influence of motion-induced HF fracture is shown in Fig. 2.

\subsection{Theoretical SA model}

To derive the morphological SA equation theoretically and study SA distribution form and formation mechanism, we introduced the calculation model of the coal/rock mass interfacial stress for the optimization of the theoretical SA model. The SA stress-bearing analysis is shown in Fig. 3 [21]. The arch crown undertakes uniformly distributed load $q$, which is calculated using the equation $q=\gamma H$ (where $H$ is the mining depth of the coal seam, and $\gamma$ is average volume weight of the overlying strata). The two sides of the arch body undertake uniformly distributed horizontal load $\lambda q$ ( $\lambda$ is the side pressure coefficient). $T_{C}$ is the horizontal thrust at arch crown $\mathrm{C}, F_{A X}, F_{A Y}, F_{B X}$, and $F_{B Y}$ are the constraining forces at the arch foot, $H_{\text {arch }}$ is the height of the $\mathrm{SA}, L_{\text {arch }}$ is the span of the $\mathrm{SA}$, and the axial compressive force $N_{P}$ brought by the removed part of the left semiarch acts upon point $\mathrm{P}(\mathrm{x}, \mathrm{y})$.

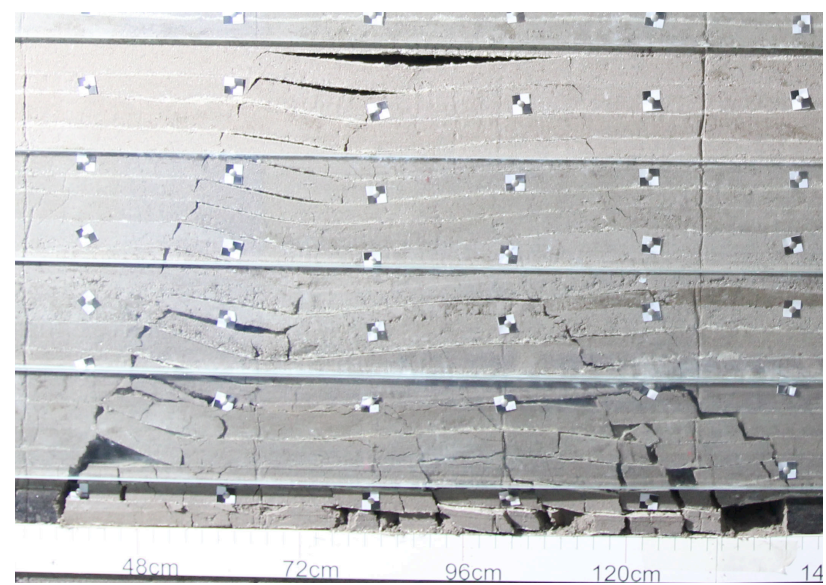

Fig. 1. Arched failure zone in similarity model experiment

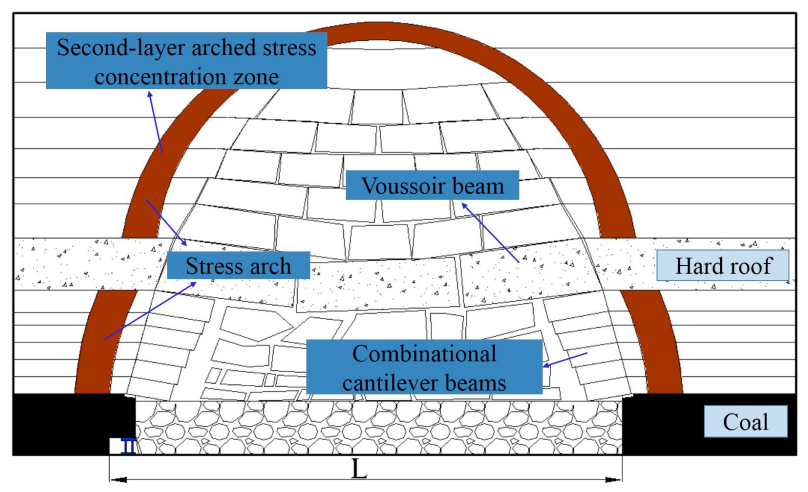

Fig. 2. Stress arch morphological analysis under the influence of hard roof

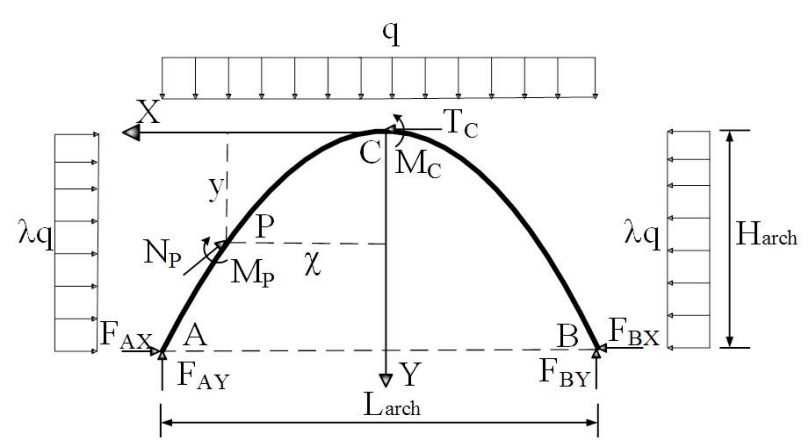

Fig. 3. Stress arch stress-bearing analysis

The torque equilibrium equation of point $\mathrm{c}$ is taken, and horizontal constraining force $F_{A X}$ at the arch foot can be obtained as follows:

$$
F_{A X}=\frac{q}{8 H_{\text {arch }}}\left(L_{\text {arch }}^{2}-4 \lambda H_{\text {arch }}^{2}\right)
$$

An arbitrary point $\mathrm{p}$ is taken from the left span of the SA, and the following equilibrium equation can be obtained through the stress bearing analysis, as follows: 
Xia Binwei, Fu Yuanhao, Zhang Xuan, Gong Tao, and Hu Ke/

Journal of Engineering Science and Technology Review 12 (1) (2019) 153 - 162

$$
T_{C} y-\frac{1}{2} q x^{2}-\frac{1}{2} q \lambda y^{2}=0
$$

The equilibrium equation of the force along the $\mathrm{x}$ axis is presented as follows:

$$
T_{C}=F_{A X}+\lambda q H_{\text {arch }}
$$

According to the equilibrium equation of the force in $\mathrm{x}$ direction and torque equation of point $\mathrm{p}$, the reasonable arch axis equation of the SA can be obtained as follows:

$$
x^{2}+\lambda y^{2}-\left(\lambda H_{\text {arch }}+\frac{L_{\text {arch }}^{2}}{4 H_{\text {arch }}}\right) y=0
$$

When $\lambda \neq 0$, the following can be obtained through conversion:

$$
\frac{x^{2}}{(U \sqrt{\lambda})^{2}}+\frac{(y-U)^{2}}{U^{2}}=1
$$

$$
\text { where } U=\frac{1}{2} H_{\text {arch }}+\frac{L_{\text {arch }}^{2}}{8 H_{\text {arch }} \lambda} \text {. }
$$

According to Equation (5), SA shape is a part of the elliptic curve, where its horizontal semiaxis length is $U \sqrt{\lambda}$; the vertical semiaxis length is $\mathrm{U}$; and the coordinate of the center point of the circle is $(0, \mathrm{U})$, which is located below horizontal line $\mathrm{AB}$ of the roof in the stope.

According to Equation (1), SA height can be obtained as follows:

$$
H_{\text {arch }}=\frac{1}{2 \lambda q}\left(\sqrt{4{F_{A X}}^{2}+\lambda q^{2} L_{\text {arch }}^{2}}-2 F_{A X}\right)
$$

According to the calculation model of the coal/rock mass interfacial stress [22], the horizontal shear resistance $F_{H}$ at the arch foot is presented as follows:

$$
F_{H}=\int_{x_{0}}^{x_{t}} \tau_{x y} d x
$$

where the distance from coal/rock wall to the peak stress is calculated as $x_{0}=\frac{h}{2 f} \frac{1-\sin \varphi}{1+\sin \varphi} \ln \left(\frac{k \gamma H}{N}\right)$, the distance from the peak stress to the primary rock stress is presented as $x_{t}=x_{0}+\frac{h}{2 f \lambda} \ln k$, and the tangential stress on the sliding plane is represented as $\tau_{x y}=C_{0}+\delta_{y} \tan \varphi_{u}$.

The horizontal constraining force of the arch foot is the horizontal shear resistance, $F_{A X}=F_{H}$ is the set in Equation (1), and then the arch height under critical state can be solved.

According to the above derivation process, an arched stress concentration zone is formed in the surrounding rocks of the stope, and SA is formed in the surrounding rocks under the self-organizing effect after coal seam mining. The SA body is inside the unmined coal/rock mass around the stope, arch foot is located at the edge of the unmined coal seam at the side wing, and horizontal thrust at the arch foot consists of the horizontal shear resistance of surrounding rocks in the two walls. SA is not a single arched path line but an arch shell structure with certain thickness; its internal boundary consists of peak stresses in the strata, and the influencing SA width extends to the primary rock stress zone.

\subsection{The MEESA under the influence of motion-induced HF fracture}

According to SA morphological analysis under the influence of motion-induced HF fracture in section 3.1 and its morphological equation derived in section 3.2, MEESA under the influence of motion-induced HF fracture was derived.

When the SA expands to the HF, its morphology experiences deformation due to the HF, and its horizontal development is temporarily interrupted. With the continuous advancement of the working face, the HF experiences deformation, fracture, motion, and subsidence, and the nextlayer arched stress concentration zone on the basis of the HF are formed within the bearing scope of the HF. The morphological evolutions of the SA in different motion phases of the overlying strata and the rock beam structural evolution in the failure zone can be divided into different phases according to the fracturing order of the HF.

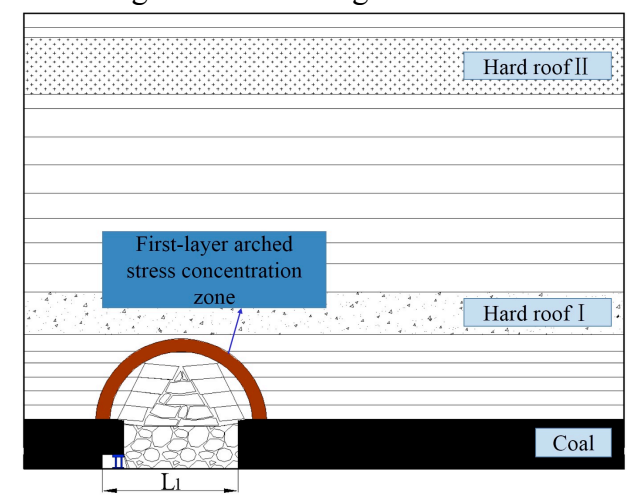

(a)

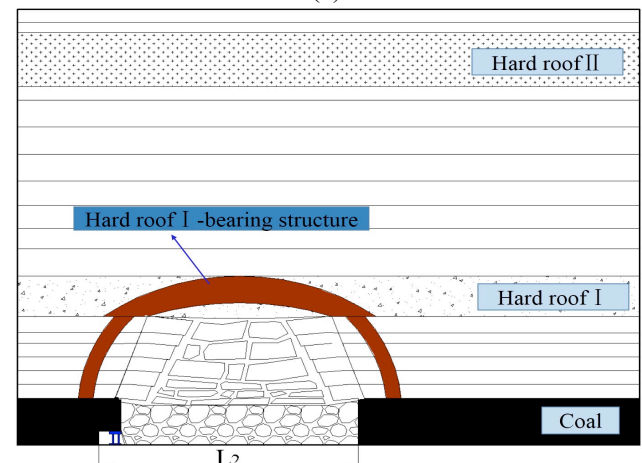

(b)

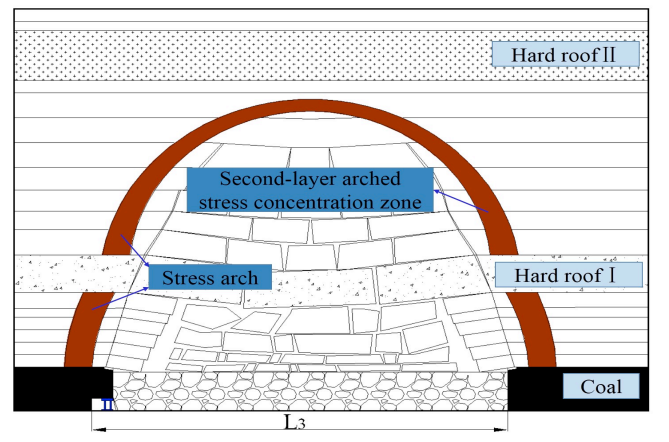

(c)

Fig. 4. Morphological evolution of stress arch under the influence of hard roof. (a) Arch-shaped expansion phase. (b) Semi-arch-shaped expansion phase. (c) Calabash-shaped expansion phase 
Xia Binwei, Fu Yuanhao, Zhang Xuan, Gong Tao, and Hu Ke/

Journal of Engineering Science and Technology Review 12 (1) (2019) 153 - 162

When the advancing distance of the working face is $L_{1}$ (Fig. 4a), SA (the first-layer arched stress concentration zones) does not expand to the first-layer HF, thereby presenting arch-shaped free expansion in both vertical and transverse directions. The SA itself exists in the unfractured overlying strata. The pressure relief zone is located below SA. At the same time, the morphological equation of the first-layer arched stress concentration zone is as follows:

$$
\frac{x^{2}}{\left(U_{1} \sqrt{\lambda_{1}}\right)^{2}}+\frac{\left(y-U_{1}\right)^{2}}{U_{1}^{2}}=1
$$

where $U_{1}=\frac{1}{2} H_{\text {arch } 1}+\frac{L_{\text {arch } 1}{ }^{2}}{8 H_{\text {arch } 1} \lambda_{1}}$, and $\lambda_{1}$ is the side pressure coefficient of the overlying strata.

The arch height of the first-layer arched stress concentration zone $H_{\text {arch1 }}$ is calculated as follows:

$$
H_{\text {arch1 }}=\frac{1}{2 \lambda_{1} q_{1}}\left(\sqrt{4{F_{H 1}^{2}+\lambda_{1} q_{1} L_{\text {arch } 1}^{2}}^{2}}-2 F_{H 1}\right)
$$

where $L_{\text {arch } 1}$ is the span of the first-layer arched stress concentration zone, $q_{1}$ is the load of the overlying strata, and $F_{H 1}$ is the horizontal shear resistance at the arch foot on two walls.

When the advancing distance of the working face is $L_{2}$ (Fig. 4b), SA expands upward until it reaches the first-layer $\mathrm{HF}$, which experiences bending subsidence. Then, a rock beam bearing structure is formed, and SA cannot get over the HF in developing upward. When the first-layer HF is unfractured, SA presents semi-arch-shaped transverse expansion.

When the advancing distance of the working face is $L_{3}$ (Fig. 4c), the first-layer HF is fractured, SA rapidly expands upward and the second-layer arched stress concentration zone is formed in the overlying strata. Then, SA (the firstlayer and second-layer arched stress concentration zones) presents calabash shape. In the failure zone, a voussoir beam structure is formed due to the fracture of the first-layer HF. The morphological equation of the second-layer arched stress concentration zone is as follows:

$\frac{x^{2}}{\left(U_{2} \sqrt{\lambda_{k 1}}\right)^{2}}+\frac{\left(y-U_{2}\right)^{2}}{U_{2}^{2}}=1$

where $U_{2}=\frac{1}{2} H_{\text {arch } 2}+\frac{L_{\text {arch } 2}{ }^{2}}{8 H_{\text {arch } 2} \lambda_{k 1}}$, and $\lambda_{k 1}$ is the side pressure coefficient of the overlying strata on the first-layer HF.

The arch height of the second-layer arched stress concentration zone $H_{\text {arch } 2}$ is calculated as follows:

$$
H_{\text {arch } 2}=\frac{1}{2 \lambda_{k 1} q_{k 1}}\left(\sqrt{4{F_{H k 1}^{2}}^{2}+\lambda_{k 1} q_{k 1} L_{\text {arch } 2}^{2}}-2 F_{H k 1}\right)
$$

where $L_{\text {arch } 2}$ is the span length of the second-layer arched stress concentration zone, $q_{k 1}$ is the load in the overlying strata on the first-layer $\mathrm{HF}$, and $F_{H k 1}$ is the horizontal shear resistance at the arch foot in the second-layer arched stress concentration zone.

$L_{\text {arch } 2}$ is calculated as follows:

$L_{\text {arch } 2}=L_{C 1}+2 x_{01}$

where $L_{C 1}$ is the initial caving interval of the first-layer HF, and $x_{01}$ is the distance from the fracturing point of the firstlayer $\mathrm{HF}$ to the peak bearing pressure.

$L_{C 1}$ is calculated as follows:

$L_{C 1}=h_{k 1} \sqrt{\frac{2 \delta_{k 1}}{q_{k 1}}}$

where $\delta_{k 1}$ is the tensile strength of the first-layer HF, and $h_{k 1}$ is thickness of the first-layer HF.

As the working face is continuously advanced, the SA expands upward until it reaches the second-layer HF. As the second-layer HF experiences plastic deformation, a rock beam bearing structure is formed on the second-layer HF. Outside the failure zone, the SA experiences continuous morphological changes under the influence of the HF. The rock beam structure in the failure zone experiences gradual evolution with expansion of the SA under the influence of motion-induced fracture of the HF.

According to the inference above, when the advancing distance of the working face is $L_{m+1}$, the SA morphology continuously changes after collapse and instability of the $(m$ 1)th-layer HF, thereby controlling expansion of the rock beam structure in the lower failure zone. The morphological equation of the $m$ th-layer arched stress concentration zone is as follows:

$\frac{x^{2}}{\left(U_{m} \sqrt{\lambda_{k(m-1)}}\right)^{2}}+\frac{\left(y-U_{m}\right)^{2}}{U_{m}{ }^{2}}=1$,

where $U_{m}=\frac{1}{2} H_{\text {archm }}+\frac{L_{\text {archm }}{ }^{2}}{8 H_{\text {archm }} \lambda_{k(m-1)}}$, and $\lambda_{k(m-1)}$ is the side pressure coefficient of the overlying strata on the $(m-1)$ thlayer $\mathrm{HF}$.

The arch height of the $m$ th-layer arched stress concentration zone $H_{\text {archm }}$ is calculated as follows:

$H_{\text {archm }}=\frac{1}{2 \lambda_{k(m-1)} q_{k(m-1)}}\left(\sqrt{4 F_{H k(m-1)}{ }^{2}+\lambda_{k(m-1)} q_{k(m-1)} L_{a r c h m}{ }^{2}}-2 F_{H k(m-1)}\right)$

where $q_{k(m-1)}$ is the load in the overlying strata on the ( $m$ 1)th-layer $\mathrm{HF}, F_{H k(m-1)}$ is the horizontal shear resistance at the arch foot in the $m$ th-layer arched stress concentration zone, and $L_{\text {archm }}$ is the span length of the $m$ th-layer arched stress concentration zone.

$L_{\text {archm }}$ is calculated as follows:

$L_{\text {archm }}=L_{C(m-1)}+2 x_{0(m-1)}$ 
Xia Binwei, Fu Yuanhao, Zhang Xuan, Gong Tao, and Hu Ke/

Journal of Engineering Science and Technology Review 12 (1) (2019) 153 - 162

where $x_{0(m-1)}$ is the distance from the fracturing point of the ( $m$-1)th-layer HF to the peak bearing pressure, and $L_{C(m-1)}$ is the initial caving interval of the $(m-1)$ th-layer HF.

$L_{C(m-1)}$ is calculated as follows:

$L_{C(m-1)}=h_{k(m-1)} \sqrt{\frac{2 \delta_{k(m-1)}}{q_{k(m-1)}}}$

where $\delta_{k(m-1)}$ and $h_{k(m-1)}$ are the tensile strength and thickness of the $(m-1)$ th-layer HF, respectively.

When the working face advanced to $L_{m+2}$, the SA expands upward until it reaches the $m$ th-layer $\mathrm{HF}$, a rock beam bearing structure is formed due to the bending subsidence of the $m$ th-layer $\mathrm{HF}$, and the SA experiences continuous morphological changes.

In summary, the SA morphology is controlled by the HF and presents dynamic evolution with the fracturing motion of the HF. Before SA expands to the HF, it presents archshaped transverse and longitudinal free expansion. After SA expands to HF, HF exerts a shielding effect on longitudinal expansion of SA and SA mainly presents semi-arch-shaped transverse expansion. After $\mathrm{HF}$ is fractured, SA rapidly expands longitudinally, and a layer of arched stress concentration zone is formed. Therefore, SA presents gradual evolution from arch and semi-arch shapes to calabash shape with the advancing distance of the working face, and HF exerts a constraining effect on the SA. After the SA expands to HF, linkage effect existed between the fracture of the HF and the expansion of the SA, thereby influencing the motion of the rock beam structure in the failure zone.

\section{Experimental results analysis}

\subsection{MESA numerical simulation analysis under the influence of $\mathrm{HF}$}

To verify the correctness of MEESA under the influence of the HF and study stress distribution features in the SA, we used FLAC3D software to carry out a numerical simulation study in this section.

Numerical simulation was carried out under the background of engineering geological conditions of one working face in Datong Coal Mine. The coal and rock mechanical parameters are shown in Table 1. To improve the operating rate and for convenient observation, we used a 2D model (model size: $300 \mathrm{~m} \times 250 \mathrm{~m}$ [length $\times$ height]), and the number of grid cells was 223,200 . Free boundary was adopted as the upper boundary of the model, while fixed boundary was used as the lower boundary, and the horizontal displacements of left and right boundaries were constrained. The distance of $100 \mathrm{~m}$ was reserved for both sides of the model to eliminate the boundary effect, and the working face advanced along the positive direction of $\mathrm{X}$ axis.
Mining at $4 \mathrm{~m}$ was simulated every time $(100 \mathrm{~m})$. The coal seam thickness was $10 \mathrm{~m}$. The distance from the HF to the coal seam was $60 \mathrm{~m}$, and the thickness of HF was $20 \mathrm{~m}$, as shown in Fig. 5.

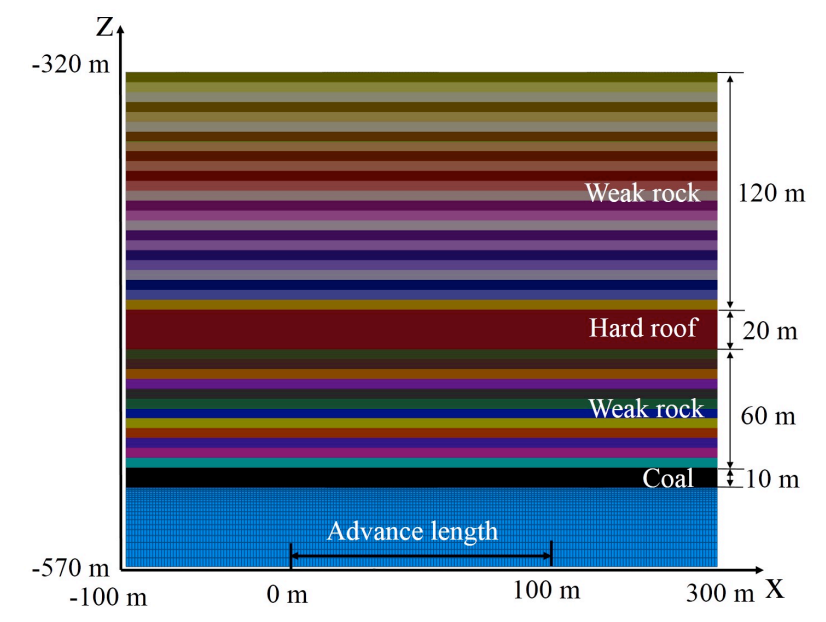

Fig. 5. Geometric model

The maximum principal stress and plastic zone graphs of the surrounding rocks in the stope under different advancing distances are shown in Fig. 6. After the excavation of the coal seam, the principal stress in the overlying strata experiences deflection, and an arched stress transfer path is formed. When stress concentration exceeds rock mass strength, the rock mass experience plastic deformation. With the advancement of the working face, the plastic deformation zone gradually expands, the rock strata fall under the effect of gravity stress, and the stress concentration zone is transferred into the deep parts of coal and rock. The overlying strata experience failure when the advancing distance of the working face is $32 \mathrm{~m}$. The height of the plastic failure zone and the SA are $47 \mathrm{~m}$ and $36 \mathrm{~m}$ respectively. The partial SA crown is located in the bending subsidence zone of coal and rock, and the stress inside the $\mathrm{SA}$ is in the range of 11-14 MPa, as shown in Fig. 6a. When the advancing distance of the working face is $60 \mathrm{~m}$, the failure scope and degree in the overlying strata increase and the height of the plastic failure zone is $78 \mathrm{~m}$. HF experiences plastic bending deflection, and maximum stress within the bearing scope of the HF is $17 \mathrm{MPa}$, as shown in Fig. $6 \mathrm{~b}$. When the advancing distance of the working face is $88 \mathrm{~m}$, the height of the plastic failure zone is $125 \mathrm{~m}, \mathrm{HF}$ is fractured, and the overlying strata go through deformation and failure. The second-layer arched stress concentration zone is formed, its height is $42 \mathrm{~m}$. The plastic deformation height is $45 \mathrm{~m}$, the maximum stress within the bearing scope of the $\mathrm{HF}$ is $18.6 \mathrm{MPa}$, and the stress in the SA is in the range of 13-15.6 MPa, as shown in Fig. 6c. The motioninduced HF fracture controls the evolutionary expansion of the SA.

Table 1. Coal and rock physical and mechanical parameters

\begin{tabular}{l|l|l|l|l|l|l}
\hline Lithology & Density $\left(\mathbf{k g} / \mathbf{m}^{\mathbf{3}}\right)$ & Bulk modulus $(\mathbf{G P a})$ & Shear modulus (GPa) & Cohesion (MPa) & $\begin{array}{l}\text { Frictional angle } \\
\left({ }^{\circ}\right)\end{array}$ & $\begin{array}{l}\text { Tensile strength } \\
(\mathbf{M P a})\end{array}$ \\
\hline hard roof & 2510 & 7.07 & 5.98 & 7.0 & 37 \\
soft strata & 2873 & 6.67 & 5.00 & 4.0 & 6 \\
coal & 1380 & 2.60 & 1.10 & 2.5 & 33 \\
base rock & 2460 & 6.67 & 5.00 & 1.0 & 30 \\
\hline
\end{tabular}


Xia Binwei, Fu Yuanhao, Zhang Xuan, Gong Tao, and Hu Ke/

Journal of Engineering Science and Technology Review 12 (1) (2019) 153 - 162
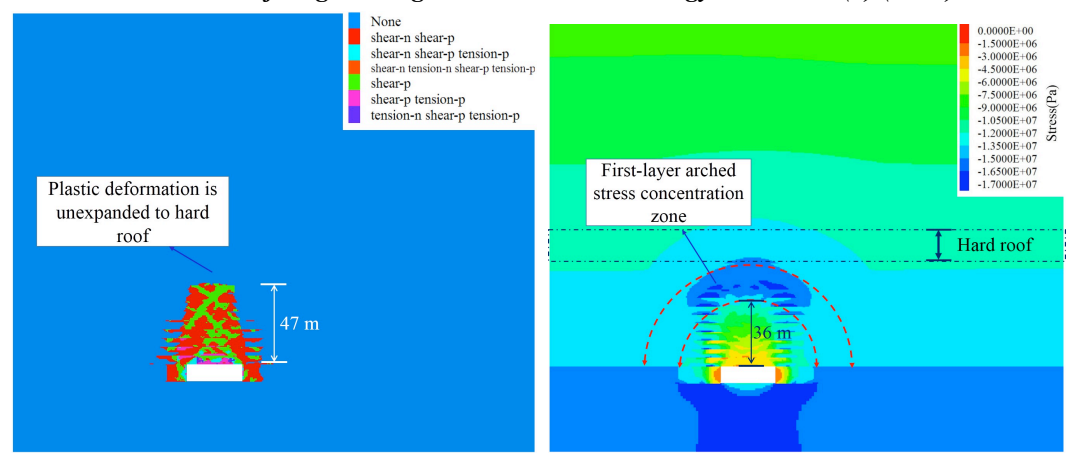

(a)
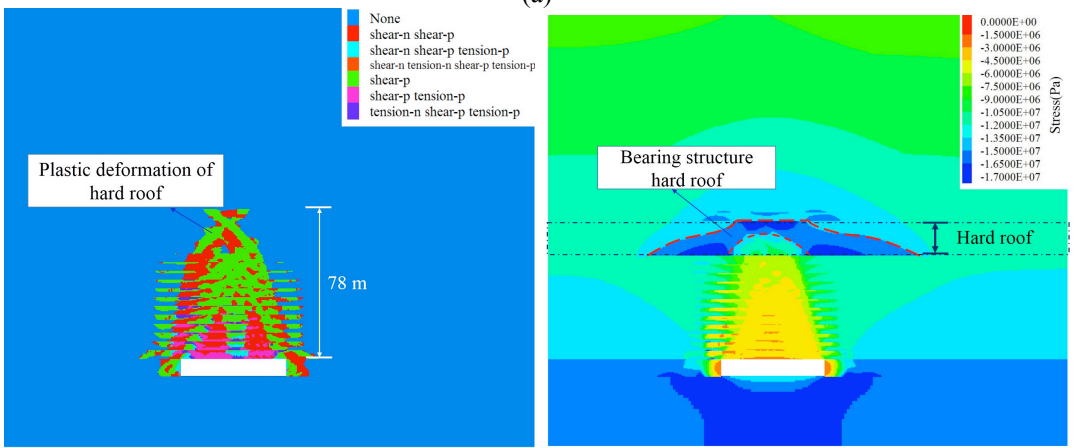

(b)
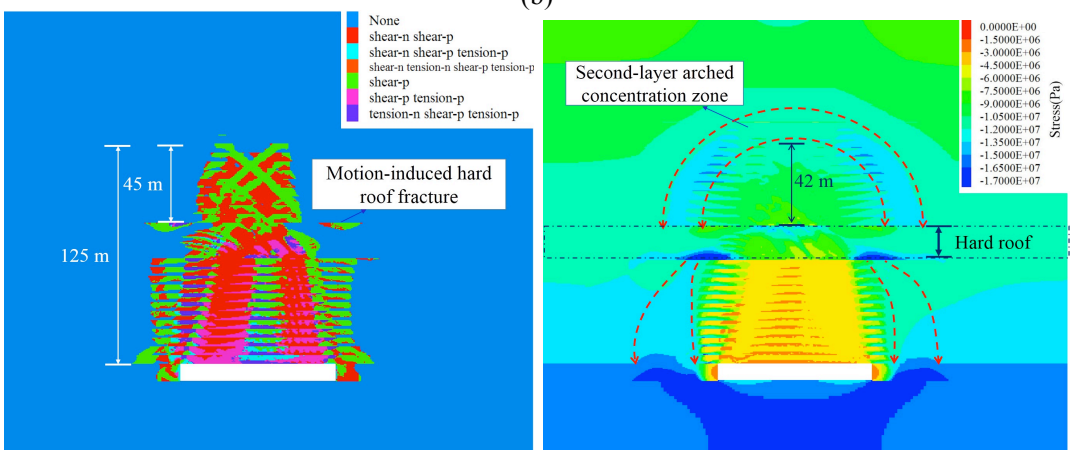

(c)

Fig.6. Evolution of plastic zone and maximum principal stress under different advancing distances. (a) When the advancing distance is $32 \mathrm{~m}$. (b) When the advancing distance is $60 \mathrm{~m}$. (c) When the advancing distance is $88 \mathrm{~m}$

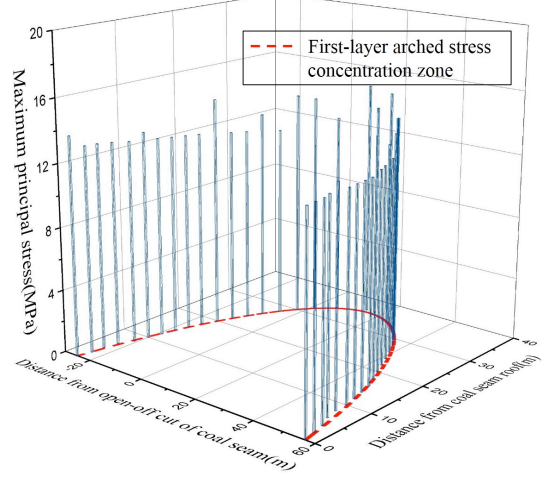

(a)

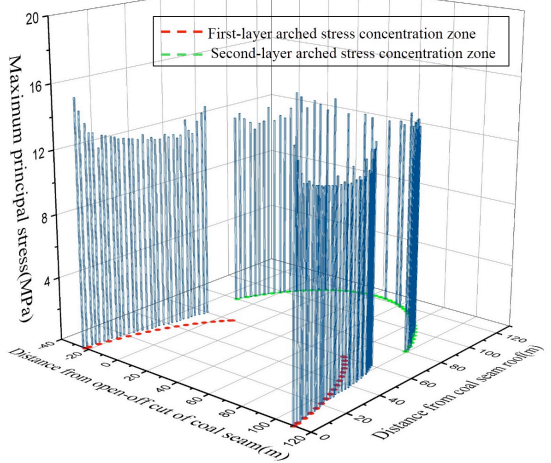

(b)

Fig.7. Morphological fitting graphs of the SA under different advancing distances. (a) When the advancing distance is $32 \mathrm{~m}$. (b) When the advancing distance is $88 \mathrm{~m}$

The internal boundary equations of the SA in different phases are calculated based on simulation conditions, and the calculation conditions are as follows: volume weight of the overlying strata $\gamma=0.025 \mathrm{MN} / \mathrm{m}^{3}$, friction coefficient at the coal seam $f_{\text {coal }}=0.26$, friction coefficient at the HF layer $f_{\text {hard }}=0.5$, side pressure coefficient $\lambda=1.5$, stress concentration factor $k=1.53$, internal friction angle in the coal seam $\varphi_{\text {caol }}=30^{\circ}$, internal friction of the $\mathrm{HF} \varphi_{\text {hard }}=$ $38^{0}$, internal friction angle on the sliding plane of coal/rock mass $\varphi_{u}=25^{\circ}$, and interfacial cohesion $C_{0}=2.5 \mathrm{MPa}$. The data above are substituted into Equations (8) and (9) to obtain MEESA under different advancing distances. When the advancing distance is $32 \mathrm{~m}$, the internal boundary 
Xia Binwei, Fu Yuanhao, Zhang Xuan, Gong Tao, and Hu Ke/

Journal of Engineering Science and Technology Review 12 (1) (2019) 153 - 162

equation of the SA is $\frac{(x-16)^{2}}{46.1^{2}}+\frac{(y+30)^{2}}{65.3^{2}}=1$. When the advancing distance is $88 \mathrm{~m}$, the internal boundary equations of the SA are $\frac{(x-44)^{2}}{68.3^{2}}+\frac{(y+21.29)^{2}}{96.35^{2}}=1$ (the first-layer arched stress concentration zone) and $\frac{(x-44)^{2}}{68.48^{2}}+\frac{(y-28.3)^{2}}{94^{2}}=1$ (the second-layer arched stress concentration zone).

To verify the MEESA under the influence of the HF, we monitored the maximum principal stress position and value at each stratum in the simulating mining process. The monitoring data are fitted with MEESA, and the fitting results are shown in Fig. 7. When the advancing distance is $32 \mathrm{~m}$, the monitoring data fit well with the morphological equations. When the advancing distance is $88 \mathrm{~m}$, the arched stress transfer path formed in the first-layer arched stress concentration zone is incomplete due to the influence of the $\mathrm{HF}$, however, the fit between the second-layer arched stress concentration zone and morphological equations is extremely good. The fitting results prove the correctness of MEESA under the influence of the HF.

The results indicate that coal seam mining breaks the stress balance in the primary rock; stress is redistributed in the strata; stress concentration and dissipation occurs; SA is formed; stress distribution is nonuniform in SA, and the stresses in the arch foot and crown are the maximum. After the SA expands to the HF, SA experiences dynamic evolution with motion-induced fracture of the HF, and the HF controls expansion of the SA and bears the loads in the overlying strata.

\subsection{Engineering case}

For example, in the stope of Datong Mine Area, the MEESA was used to calculate the support resistance on the working face. After the multilayer Jurassic thin coal seams in the overlying strata in Datong mine area are mined, 3\#-5\# carboniferous ultrathick coal seams are mainly mined at present, and the support resistance on the working face mainly comes from multilayer combinational cantilever beams and key strata-fracturing masses in the failure zone. According to key strata theory and physical-mechanical parameters of coal and rock, key strata position and their weighting interval can be determined, as shown in Table 2 .

According to MEESA, the SA scope and number of rock strata in the failure zone under different advancing distances are determined, and the resistance calculation equation of the working face is used to calculate the resistance of the support, as follows [23]:

$$
P_{Z}=G_{1}+G_{2}+G_{3}+G_{4}
$$

where $G_{1}=\frac{1}{2 c} \sum_{i=1}^{Z} P_{i}\left(l_{i}+h_{i} \cot \alpha_{i}\right)$ is the gravity of the roof experiencing fracture and instability,
$G_{2}=\frac{1}{c} \sum_{j=1}^{Z-1} R_{i} h_{i} \cot \alpha_{i}$ is the additional acting force between the roof layers in the overlying strata, $G_{3}=\frac{K_{d} B P_{d}}{c}$ is the roof coal gravity, and $G_{4}=\frac{1}{c} \sum_{j=1, k=k_{1}+1}^{m-1, k_{m-1}+1} \frac{1}{f_{B_{j}}}\left(K_{B_{j}} S_{B_{j}}-P_{B_{j}}\right)\left(\begin{array}{l}h_{k}-w_{j}+l_{k} f_{B_{j}} \\ +h_{k} f_{B_{j}} \cot \alpha_{B_{j}}\end{array}\right) \quad$ is the acting force generated due to mutual extrusion and friction between masses in the roof fracture in the failure zone.

The calculation conditions are as follows: mining depth $H=440 \mathrm{~m}$, coal seam thickness $h_{0}=15.6 \mathrm{~m}$, average volume weight of the overlying strata $\gamma=0.025 \mathrm{MN} / \mathrm{m} 3$, friction coefficient between coal seams $f_{\text {coal }}=0.26$, friction coefficient between roof layers in the key strata $f_{\text {key }}=0.8$, internal friction angle in the coal seam $\varphi_{\text {coal }}=30^{\circ}$, internal friction coefficient in the key strata $\varphi_{k e y}=38^{\circ}$, side pressure coefficient $\lambda=1.8$, internal friction angle on the sliding plane of coal/rock mass $\varphi_{u}=25^{\circ}$, and interfacial cohesion $C_{0}=2.5 \mathrm{MPa}$. Before the instability and fracture of key strata I, SA presents semi-arch-shaped transverse expansion. The height of the rock beam structure in the failure zone is the distance from key strata I to the coal seam, which is $10.5 \mathrm{~m} ; 1$-3\# strata are in the failure zone; and the support resistance on the working face is $1.99 \mathrm{MN}$, which can be obtained through the resistance calculation equation. When the advancing distance is $66.45 \mathrm{~m}$, key strata I experiences critical instability, and the second-layer arched stress concentration zone is formed. The height of the second-layer arched stress concentration zone is $27.1 \mathrm{~m}$, which is greater than the distance from key strata II to key strata I, by using Equation (10). Hence, the height of the second-layer arched stress concentration zone is determined after the fracture of key strata I, and soft rocks synchronously cave with key strata I. Rock stratum height in the failure zone is $44.5 \mathrm{~m}, 1 \#-6 \#$ strata are in the failure zone, and the support resistance on the working face is $11.08 \mathrm{MN}$. When the advancing distance of the working face is $73.1 \mathrm{~m}$, key strata II experiences critical instability, the third-layer arched stress concentration zone is formed, and the arch height is calculated as $25.9 \mathrm{~m}$ by using Equation (14). Hence, the SA height is $94.6 \mathrm{~m}$. The 1\#-9\# strata are in the failure zone, and the support resistance on the working face is 13.13 $\mathrm{MN}$. According to the field observation [23], the support resistance in Datong Mine Area is in the range of 0-14 MN. The theoretical calculations agree with field observation, and the study can provide a theoretical basis for mine pressure control.

Table 2. Physical and mechanical parameters of coal and rock and roof weighting interval of key strata

\begin{tabular}{|c|c|c|c|c|c|c|c|c|}
\hline Number & Lithology & $\begin{array}{l}\text { Thickness } \\
\text { (m) }\end{array}$ & $\begin{array}{l}\text { Density } \\
\left(\mathrm{kg} / \mathrm{m}^{3}\right)\end{array}$ & $\begin{array}{l}\text { Tensile } \\
\text { strength } \\
\text { (MPa) }\end{array}$ & $\begin{array}{l}\text { Elasticity } \\
\text { modulus } \\
(\text { GPa) }\end{array}$ & $\begin{array}{l}\text { Key } \\
\text { strata } \\
\text { position }\end{array}$ & $\begin{array}{l}\text { Initial } \\
\text { caving } \\
\text { interval } \\
\text { (m) }\end{array}$ & $\begin{array}{l}\text { Periodic } \\
\text { weighting } \\
\text { interval } \\
\text { (m) }\end{array}$ \\
\hline $\begin{array}{l}10 \\
9 \\
8\end{array}$ & $\begin{array}{l}\text { medium siltstone } \\
\text { medium gritstone } \\
\text { silt/sand interbed }\end{array}$ & $\begin{array}{l}10.5 \\
10.9 \\
17.0\end{array}$ & $\begin{array}{l}2628 \\
2534 \\
2587\end{array}$ & $\begin{array}{l}7.3 \\
7.0 \\
5.2\end{array}$ & $\begin{array}{l}78.3 \\
14.3 \\
23.4\end{array}$ & & & \\
\hline
\end{tabular}


Xia Binwei, Fu Yuanhao, Zhang Xuan, Gong Tao, and Hu Ke/

Journal of Engineering Science and Technology Review 12 (1) (2019) 153 - 162

\begin{tabular}{l|l|l|l|l|l|l|l|l|}
7 & silt/sand interbed & 23.0 & 2587 & 5.2 & 23.4 & II & 73.10 \\
6 & silt/sand interbed & 9.0 & 2587 & 5.2 & 23.4 & & \\
5 & calcareous clay & 6.0 & 2376 & 4.8 & 15.8 & \\
& thin coal seam & 2.4 & 1426 & 2.6 & 2.8 & \\
4 & fine sandstone & 16.6 & 2438 & 5.6 & 23.6 & I & 66.45 \\
3 & magmatic rock & 1.7 & 2595 & 8.6 & 40.2 & \\
& thin coal seam & 4.2 & 1426 & 2.6 & 2.8 & \\
1 & siltstone & 2.9 & 2728 & 4.0 & 23.4 & \\
0 & magmatic rock & 1.7 & 2595 & 8.3 & 39.8 & \\
\end{tabular}

\section{Conclusions}

To study the morphological evolution laws of the mininginduced SA under the influence of motion-induced fracture of the HF, we introduced a calculation model of the coal/rock mass interfacial stress for the optimization of the SA model, on the basis of which the MEESA under the influence of the HF was derived. Flac3D software was used to simulate the MESA under the influence of the HF, and the result was fitted with the derived equation for verification. The main conclusions could be drawn as follows:

(1) The calculation model of coal/rock mass interfacial stress is introduced to calculate the horizontal thrust at the SA foot, and the mechanical model of the SA is optimized.

(2) The SA morphology is controlled by the HF and experiences dynamic evolution with the fracturing motion of the HF. Before SA expands to HF, it presents horizontal and transverse arch-shaped free expansion. After SA expands to the HF, HF can exert shielding effect on longitudinal expansion of SA, and SA is mainly manifested by semiarch-shaped transverse expansion. After HF becomes fractured, SA rapidly goes longitudinal expansion, the nextlayer arched stress concentration zone is formed, and the SA presents calabash-shaped expansion. The SA morphology gradually evolves from arch and semi-arch shapes to calabash shape successively with motion-induced fracture of the HF, and HF has a constraining effect on SA.

(3) Numerical simulation method is used to analyze the stress distribution features in SA under the influence of the
HF and verify correctness of the MEESA, and the fitting result is good. Equations are used to calculate the support resistance on the engineering field, and the results agree well with the monitoring mine pressure data.

In summary, the derived MEESA under the influence of motion-induced fracture of the $\mathrm{HF}$ can describe the evolutionary characteristics of the mining-induced SA extremely well, thereby laying a theoretical foundation for the further analysis of mine pressure behavior and stability of the surrounding rocks. However, this study only investigated the influences of motion-induced fracture of the HF under different advancing distances on the MESA but did not analyze the influence of the parametric change in the HF on the SA morphology. Therefore, further works should be carried out to study the influences of thickness, stratum position, and mechanical features of the HF on the SA morphology in the stope.

\section{Acknowledgements}

This study was funded by the National Natural Science Foundation of China (No. 51104191), the China Postdoctoral Science Foundation (2016M602655), and the Program for Changjiang Scholars and Innovative Research Team in University of China (No. IRT13043).

This is an Open Access article distributed under the terms of the Creative Commons Attribution License

\section{References}

1. Shi, Z. K., "Green mining technology of mining in China". Electronic Journal of Geotechnical Engineering, 20(17), 2015, pp.9961-9968.

2. Peng, S. S., "Topical areas of research needs in ground control - A state of the art review on coal mine ground control". International Journal of Mining Science and Technology, 25(1), 2015, pp.1-6.

3. Kang, H. P., Lv, H. W., Gao, F. Q., Meng, X. Z., Feng, Y. J., "Understanding mechanisms of destressing mining-induced stresses using hydraulic fracturing". International Journal of Coal Geology, 196, 2018, pp.19-28.

4. Gao, F. Q., Stead, D., Kang, H. P., "Numerical simulation of squeezing failure in a coal mine roadway due to mining-induced stresses". Rock Mechanics and Rock Engineering, 48(4), 2015, pp.1635-1645.

5. Corkum, A. G., Board, M. P., "Numerical analysis of longwall mining layout for a Wyoming Trona mine". International Journal of Rock Mechanics and Mining Sciences, 89, 2016, pp.94-108.

6. Xie, G. X., Yang, K., "Study of macro stress shell evolving characteristic of rock surrounding face". Yanshilixue Yu Gongcheng Xuebao/Chinese Journal of Rock Mechanics and Engineering, 29(1), 2010, pp.2676-2680.
7. Hou, P., Gao, F., Ju, Y., Cheng, H. M., Gao, Y. A., Xue, Y., Yang, Y. G., "Changes in pore structure and permeability of low permeability coal under pulse gas fracturing". Journal of Natural Gas Science and Engineering, 34, 2016, pp.1017-1026.

8. Bai, Q. S., Tu, S. H., Wang, F. T., Zhang, C., "Field and numerical investigations of gateroad system failure induced by hard roofs in a longwall top coal caving face". International Journal of Coal Geology, 173, 2017, pp.176-199.

9. Xuan, D. Y., Xu, J. L., Zhu, W. B., "Dynamic disaster control under a massive igneous sill by grouting from surface boreholes". International Journal of Rock Mechanics and Mining Sciences, 71, 2014, pp.176-187.

10. Wang, S. R., Li, N., Li, C. L., Hagan, P., "Mechanics evolution characteristics analysis of pressure-arch in fully-mechanized mining field". Journal of Engineering Science and Technology Review, 7(4), 2014, pp.40-45.

11. Vaziri, H. H., Jalali, J. S., Islam, R., "An analytical model for stability analysis of rock layers over a circular opening". International Journal of Solids and Structures, 38(21), 2001, pp.3735-3757.

12. Zhu, Z., Zhu, C., Yuan, H. P., "Distribution and evolution characteristics of macroscopic stress field in gob-side entry retaining by roof cutting". Geotechnical and Geological Engineering, 2019, doi: 10.1007/s10706-019-00813-4. 
Xia Binwei, Fu Yuanhao, Zhang Xuan, Gong Tao, and Hu Ke/

Journal of Engineering Science and Technology Review 12 (1) (2019) 153 - 162

13. Shabanimashcool, M., Li, C. C., "Analytical approaches for studying the stability of laminated roof strata". International Journal of Rock Mechanics and Mining Sciences, 79, 2015, pp.99-108.

14. Xie, G. X., Wang, L., "Lithologic effect on the mechanical characteristics of mining-induced stress shell". Meitan Xuebao/Journal of China Coal Society, 38(1), 2013, pp.44-49.

15. Li, C. C., "Principles of rockbolting design". Journal of Rock Mechanics and Geotechnical Engineering, 9(3), 2017, pp.396414.

16. Angus, D.A., Fisher, Q. J., Segura, J. M., Verdon, J. P., Kendall, J. M., Dutko, M., Crook, A. J. L., " Reservoir stress path and induced seismic anisotropy: results from linking coupled fluidflow/geomechanical simulation with seismic modelling". Petroleum Science, 13(4), 2016, pp.669-684.

17. Kong, X. X., Liu, Q. S., Zhang, Q. B., Zhao, J., "A method to estimate the pressure arch formation above underground excavation in rock mass". Tunnelling and Underground Space Technology, 71, 2018, pp.382-390.

18. Yang, J. H., Wang, S. R., Wang, Y. G., Li, C. L., “Analysis of arching mechanism and evolution characteristics of tunnel pressure arch". Jordan Journal of Civil Engineering, 9(1), 2015, pp.125-132.
19. Dancygier, A. N., Karinski, Y. S., Chacha, A., "A model to assess the response of an arched roof of a lined tunnel". Tunnelling and Underground Space Technology, 56, 2016, pp.211-225.

20. Yang, K., XIE, G. X. "Modeling and analyzing on the development of mining induced stress shell in deep longwall mining”. Meitan Xuebao/Journal of China Coal Society, 35(7), 2010, pp.1066-1071.

21. Xia, B. W., Zhang, X., Yu, B., Jia, J. L., "Weakening effects of hydraulic fracture in hard roof under the influence of stress arch". International Journal of Mining Science and Technology, 28(6), 2018, pp.951-958.

22. Liu, J., Jiang, F., Zhu, S., "Study of dynamic and static abutment pressure around longwall face and its application". Yanshilixue Yu Gongcheng Xuebao/Chinese Journal of Rock Mechanics and Engineering, 34(9), 2015, pp.1815-1827.

23. Liu, C. Y., Yang, J. X., Yu, B., Wu, F. F., "Support resistance determination of fully mechanized top-coal caving face in extra thick seam under multi-layered hard strata". Caikuang yu Anquan Gongcheng Xuebao/Journal of Mining and Safety Engineering, 32(1), 2015, pp.7-13. 